rupture causing air embolism, and this might be the cause of the more serious type 2 decompression sickness (Walder, 1963). For this reason routine chest radiographs are advised on all hospital personnel before working in a hyperbaric environment. It is suggested that the examination should include radiographs on expiration and full inspiration to see if any localized overinflation could be found. Patients who were seen to have cysts or bullae of their lungs should be excluded from work in compressed air. Where routine chest radiographs were carried out in tunnel workers on the Clyde and such cases were excluded, there was apparently no reduction in the incidence of type 1 or type 2 decompression sickness (Davidson, 1964).

No abnormalities were noted on the chest radiographs of the Glasgow staff other than small calcified foci on two occasions. In these two subjects no change in the appearance of the chest radiograph was noted after frequent exposures to hyperbaric pressure. Moreover, in another series of studies more than 50 patients with advanced chronic respiratory disease were decompressed from pressures not exceeding 2 atmospheres without untoward consequences-one such patient had 26 compressions over a period of three years (Ledingham et al., 1968).

Aseptic necrosis of bone is a late sequel of working in compressed air, and radiographic changes may not appear until 6, 12 , or 18 months after the causative episode. When the bone lesion is next to a joint surface, as in the head of the femur or the head of the humerus, permanent disability may result. An extensive study of 241 tunnel workers at the Clyde Tunnel showed that $19 \%$ of the men had one or more bone lesions and that in $10 \%$ lesions were juxta-articular and so potentially disabling.

Among hospital personnel and those responsible for their safety there was concern that disabling bone lesions might develop. It is true that compared with tunnel workers the number of staff involved in medical hyperbaric environments is small, and the duration and number of exposures much less. In 21 of the 36 members of the staff examined radiologically, however, sufficient time has now elapsed for a bone lesion to have appeared; fortunately no radiological indication of any such lesion has emerged. So far as we are aware no comparable radiographic study at other hospital hyperbaric units has been reported.

These data at present support the claim that pressures of air in the range 1-3 atmospheres are relatively safe for use in a specialized medical hyperbaric environment. It remains entirely conjectural whether the modifications added to the conventional decompression programmes, such as the breathing of oxygen and the introduction of extra stops during decompression, have had any bearing on these findings.

\section{REFERENCES}

Anderson, B., jun., Whalen, R. E., and Saltzman, H. A. (1964). Fournal of the American Medical Association, 190, 1043

Behnke, A. R. (1940). Annals of Internal Medicine, 13, 2217

Bennett, P. B., Poulton, E. C., Carpenter, A., and Catton, M. J. (1967). Ergonomics, 10, 53 .

Davidson, J. K. (1964). Clinical Radiology, 15, 106.

Denison, D. M., Ernsting, J., Tonkins, W. J., and Cresswell, A. W. (1968). Nature, 218, 1110 .

Ledingham, I. McA. (1967). In Modern Trends in Pharmacology and Therapeutics, p. 96, edited by W. F. M. Fulton. London, Butterwherap

Ledingham, I. McA. (1969). In Recent Advances in Surgery, 7th ed., p. 45 , edited by S. Taylor. London, Churchill.

Ledingham, I. McA., Spence, A. A., Tindal, S. A. P., and Mone, J. G. (1968). Unpublished data.

McCallum, R. I. (1968). British fournal of Industrial Medicine, 25, 4. McDowall, D. G., Ledingham, I. McA., Jacobson, I., and Norman, J. N. (1965). Anesthesiology, 26, 720.

Ministry of Labour and National Service (1958). Work in Compressed Air Special Regulations (S.1. 1958, No. 61). London, H.M.S.O.

National Research Council, Committee on Hyperbaric Oxygenation (1966). Fundamentals of Hyperbaric Medicine. Washington, National Academy of Sciences.

Paulev, P. (1966). Danish Medical Bulletin, 13, 49.

Poulton, E. C., Carpenter, A., and Catton, M. J. (1963). British Medical fournal, 2, 1450.

Walder, D. N. (1963). In The Regulation of Human Respiration, p. 570 , edited by D. J. C. Cunningham and B. B. Lloyd. Oxford, Blackwell Scientific Publications.

\title{
Scintillation Scanning of Lungs in Preoperative Assessment of Carcinoma of Bronchus
}

\author{
R. H. SECKER WALKER,* M.B., M.R.C.P. ; J. L. PROVAN, † M.s., F.R.C.S.
}

[With Special Plate between Pages 330-331]

Cummary : Lung scans with the use of macroaggregated $\checkmark$ human serum albumin labelled with technetium-99m were carried out in 52 patients before thoracotomy.

Forty-three patients had carcinoma of the bronchus. Tumours less than $2 \mathrm{~cm}$. in diameter on the chest radiograph were not detected. Larger tumours showed defects in perfusion, ranging in size from the mass seen on the chest radiograph to almost absent perfusion of the entire lung. The extent of the defect in perfusion was closely related to involvement of the pulmonary vessels at the hilum by distortion, compression, or invasion by the tumour. Bronchial obstruction played a less important part in producing the defects.

The larger the defect in perfusion the greater was the involvement of the hilar and mediastinal structures and the more extensive was the surgery required. When perfusion of the affected lung was less than one-third of the total the tumour was found to be unresectable.

\section{Introduction}

About one-third of the patients with carcinoma of the bronchus undergoing thoracotomy are found to have an unresectable tumour (Gifford and Waddington, 1957 ; Price Thomas, 1960 ; Flavell, 1962 ; Barrett et al., 1963 ; Belcher and Anderson, 1965). In such cases resection is prevented by extensive spread of the disease or invasion of vital structures. Some indication of the extent of involvement of the hilar region may be seen on the chest radiograph or demonstrated by tomography. In a few centres angiocardiography has been used to show involvement of the great vessels, and this technique has proved useful in determining resectability in some instances (Wyman and Wilkins, 1958 ; Steinberg and Finby, 1959).

\footnotetext{
* Lecturer in Medicine, University College Hospital Medical School, London W.C.1.

† Senior Lecturer in Surgery, University College Hospital Medical School, London W.C.1. Present address: Department of Surgery, the Wellesley Hospital, 106 Wellesley Street East, Toronto 5, Ontario, Canada.
} 
The pattern of pulmonary arterial perfusion is readily and safely demonstrated by scintillation scanning of the lungs (Sabiston and Wagner, 1964 ; Taplin et al., 1964). This paper reports the use of this technique in the preoperative assessment of patients with carcinoma of the bronchus.

\section{Patients and Methods}

The patients were all considered on clinical and bronchoscopic grounds to have operable tumours and had been recommended for thoracotomy. The diagnosis of carcinoma of the bronchus was established by sputum cytology, biopsy at bronchoscopy or thoracotomy, or from the histology of the resected tumour.

Each patient was given $1.5-2 \mathrm{mCi}$ of technetium-99mlabelled macroaggregated human serum albumin ( ${ }^{99 m} \mathrm{Tc}-\mathrm{MAA}$ ) intravenously, and the lung scans were made by a Picker Magnascanner III. Anterior and posterior colour scans and photoscans were produced. The method of preparation of ${ }_{99 \mathrm{~m}} \mathrm{Tc}-\mathrm{MAA}$ and the scanning technique have been described previously (Secker Walker, 1968).

The scans were assessed by comparison with normal scans and with the corresponding chest radiograph. The relative pulmonary arterial perfusion of each lung was calculated from the counts of radioactivity recorded from each lung on both anterior and posterior scans expressed as a percentage of the total counts in the scan. This method correlates well with differential bronchospirometry as an estimate of relative pulmonary blood flow (Chernik et al., 1965 ; Rogers et al., 1967).

Measurement of the forced expiratory volume at 1 second (F.E.V. . $_{1}$ and the forced vital capacity (F.V.C.) were carried out by the hospital's routine spirometry service. The F.V.C. was also expressed as a percentage of the predicted value for age, sex, and height.

\section{Results}

Since November 1966 more than 800 lung scans have been carried out at University College Hospital without mishap. One hundred and eighty-three patients suspected of having a carcinoma of the bronchus have been scanned, and 113 were subsequently shown to have this disease. Fifty-two patients underwent thoracotomy, and the final diagnosis in these patients is shown in Table $\mathrm{I}$.

TABle I.-Diagnosis in 52 Patients Who Underwent Thoracotomy

$$
\text { Diagnosis }
$$

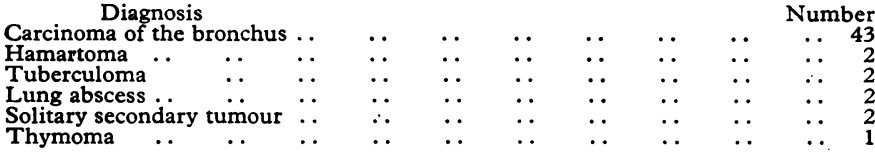

Forty-three patients ( 29 men and 14 women) with carcinoma of the bronchus were explored. Their mean age was 55.6 years, with a range of 41 to 68 years. There were 19 squamous carcinomas, 16 oat cell or anaplastic carcinomas, and 8 adenocarcinomas.

The bronchoscopic findings in these patients, all of whom were considered operable, are summarized in Table II. The patients have been divided into three groups-15 (35\%) whose tumours were subsequently found to be inoperable, 14 (32.5\%)

\begin{tabular}{|c|c|c|c|c|}
\hline TABLE II.-Bronchoscopic & Findings & Carcin & ma & chus* \\
\hline Bronchoscopic Findings & $\begin{array}{c}\text { Inoperable } \\
\text { (15) }\end{array}$ & $\begin{array}{l}\text { Pneumon- } \\
\text { ectomy } \\
\text { (14) }\end{array}$ & $\begin{array}{l}\text { Lobectomy } \\
\text { (12) }\end{array}$ & $\begin{array}{l}\text { Total } \\
\text { (41) }\end{array}$ \\
\hline 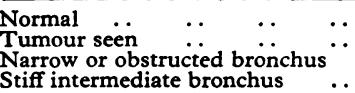 & $\begin{array}{l}5 \\
5 \\
7 \\
2\end{array}$ & $\begin{array}{l}5 \\
6 \\
6 \\
0\end{array}$ & $\begin{array}{l}8 \\
3 \\
1 \\
0\end{array}$ & $\begin{array}{r}18 \\
14 \\
14 \\
2\end{array}$ \\
\hline
\end{tabular}

- Two patients underwent segmental resection. They are not included in the ables but are referred to in the text. who underwent pneumonectomy, and $12(28 \%)$ who underwent lobectomy. Two other patients $(4.5 \%)$ who had segmental resections had normal bronchoscopies. There is little difference between the bronchoscopic findings in the inoperable and pneumonectomy groups, but a larger proportion of the lobectomy group had normal bronchoscopies.

Table III summarizes the chest radiograph findings. The hilum appeared normal in all the patients who underwent lobectomy. There was again little difference in the radiological findings between the pneumonectomy and inoperable groups, though the tumour was closely related to the hilum in five of the inoperable group as opposed to three in the pneumonectomy group. The hilum was normal in both the patients who had segmental resections.

TABLE III.-Chest Radiograph Findings in Carcinoma of Bronchus

\begin{tabular}{|c|c|c|c|c|c|c|}
\hline \multicolumn{3}{|c|}{ Chest Radiograph Findings } & \multirow{2}{*}{$\begin{array}{c}\text { Inoperable } \\
9 \\
3 \\
5 \\
7\end{array}$} & \multirow{2}{*}{\begin{tabular}{|c|}
$\begin{array}{c}\text { Pneumon- } \\
\text { ectomy }\end{array}$ \\
7 \\
2 \\
3 \\
7
\end{tabular}} & \multirow{2}{*}{ 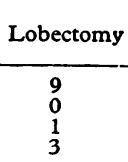 } & \multirow{2}{*}{$\begin{array}{c}\text { Total } \\
25 \\
5 \\
9 \\
17\end{array}$} \\
\hline $\begin{array}{l}\text { Localized mass } \ldots \\
\text { Abnormal hilum } \ldots \\
\text { Mass related to hilum } \\
\text { Collapse/consolidation }\end{array}$ & $\begin{array}{l}\cdots \\
\therefore \\
\therefore\end{array}$ & $\begin{array}{l}\cdots \\
\cdots \\
\cdots\end{array}$ & & & & \\
\hline
\end{tabular}

TABLE IV.-Lung Scan Findings in Carcinoma of Bronchus

\begin{tabular}{|c|c|c|c|c|c|}
\hline Lung Scan Findings & & Inoperable & $\begin{array}{l}\text { Pneumon- } \\
\text { ectomy }\end{array}$ & Lobectomy & Total \\
\hline $\begin{array}{l}\text { Normal perfusion of } \\
\text { affected lung } \\
\text { Defect corresponding to mass } \\
\text { on chest radiograph } \\
\text { Diminished perfusion of } \\
\text { affected lobe } \ldots \\
\text { Diminished perfusion of } \\
\text { adjacent lobe } \ldots \\
\text { Irregularities in perfusion } \\
\text { of opposite lung }\end{array}$ & $\cdots$ & $\begin{array}{r}0 \\
2 \\
14 \\
12 \\
4\end{array}$ & $\begin{array}{r}0 \\
5 \\
11 \\
9 \\
10\end{array}$ & $\begin{array}{l}2 \\
6 \\
6 \\
3 \\
6\end{array}$ & $\begin{array}{r}2 \\
13 \\
31 \\
24 \\
20\end{array}$ \\
\hline
\end{tabular}

The lung scan findings are summarized in Table IV. The scan on the affected side was normal in two patients who subsequently underwent lobectomy. Both had peripheral carcinomas measuring less than $2 \mathrm{~cm}$. in diameter. The lung scans of the other patients showed abnormalities which ranged in size from a localized defect in perfusion corresponding to the mass on the chest radiograph (Special Plate, Fig. 1), through diminished lobar perfusion (Special Plate, Fig. 2), to virtually absent perfusion of the affected lung (Special Plate, Fig. 3). Nearly two-thirds $(16 / 26)$ of the patients who underwent pneumonectomy or lobectomy had irregularities in perfusion of their unaffected lung, but only four of the patients with unresectable tumours did so.

The mean values $( \pm$ S.E.M.) for the spirometry tests and the relative pulmonary arterial perfusion of the affected lung are shown in Table V. There is a poor but significant correlation between the F.V.C. (expressed as a percentage of the predicted value for age, sex, and height) and the relative perfusion of the affected lung for the 41 patients in the three groups $(r=0.347$, $\mathrm{P}<0.05)$.

TABLE V.-Results of Spirometry Tests and Relative Pulmonary Arterial

\begin{tabular}{|c|c|c|c|}
\hline & Inoperable & $\begin{array}{l}\text { Pneumon- } \\
\text { ectomy }\end{array}$ & Lobectomy \\
\hline \multirow{3}{*}{$\begin{array}{l}\text { Mean F.E.V.1 as \% F.V.C. } \pm \text { S.E.M. .. } \\
\text { Mean F.V.C. as \% predicted value } \\
\text { for age, sex and height } \pm \text { S.E.M. } \\
\text { Mean perfusion of affected lung as \% } \\
\text { total pulmonary arterial perfusion } \\
\pm \text { S.E.M. } \quad . . \\
\begin{array}{llll}\text {... } & \ldots\end{array}\end{array}$} & $72 \cdot 4 \pm 2 \cdot 1$ & $69 \cdot 0 \pm 2 \cdot 5$ & $74 \cdot 3 \pm 1 \cdot 9$ \\
\hline & $79 \cdot 5 \pm 6 \cdot 2$ & $95 \cdot 2 \pm 3 \cdot 1$ & $95 \cdot 8 \pm 5 \cdot 6$ \\
\hline & $28 \cdot 5 \pm 4 \cdot 0$ & $39 \cdot 5 \pm 1 \cdot 5$ & $47 \cdot 3 \pm 1 \cdot 0$ \\
\hline
\end{tabular}

The mean F.V.C. (expressed as a percentage of the predicted value) of the inoperable group $(79 \cdot 5 \% \pm 6 \cdot 2)$ is significantly different from that of the pneumonectomy group $(95 \cdot 2 \% \pm 3 \cdot 1$, $\mathrm{P}<0.05$ ), but the differences between the lobectomy group $(95 \cdot 8 \% \pm 5 \cdot 6)$ and the other two groups are not statistically significant. There is no significant difference between the mean 
F.E.V. ${ }_{1}$ (expressed as a percentage of the F.V.C.) of the three groups.

The relative pulmonary arterial perfusion of the affected lung for all the patients who had a thoracotomy and also the values for each lung in 12 healthy subjects are shown in the Chart. The mean relative pulmonary arterial perfusion of the inoperable group $(28.5 \% \pm 4.0)$ is significantly different from both that of the pneumonectomy group $(39.5 \% \pm 1.5, \mathrm{P}<0.02)$ and that of the lobectomy group $(47.3 \% \pm 1 \cdot 0, \mathrm{P}<0.001)$.

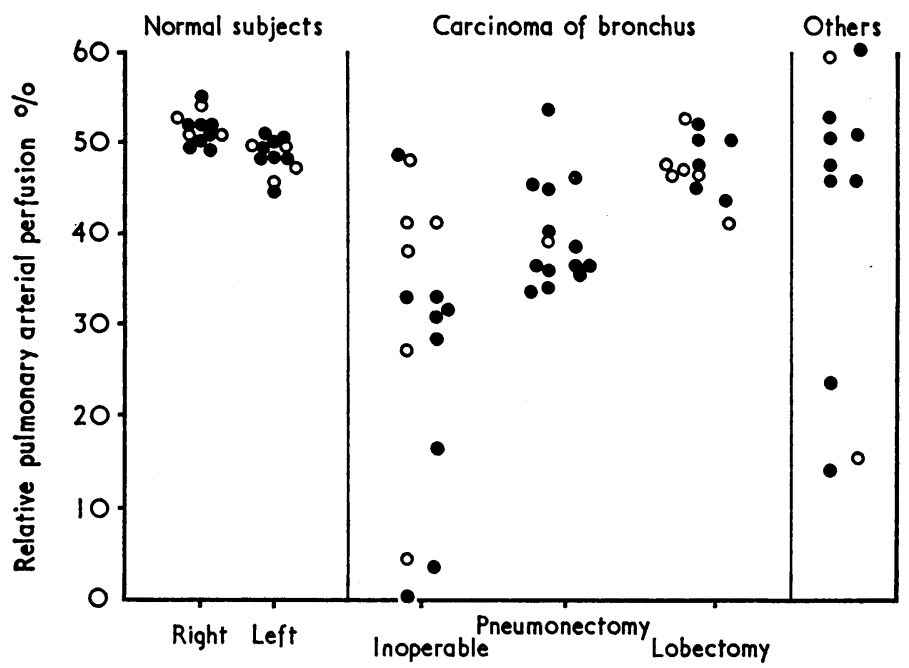

Relative pulmonary arterial perfusion of each lung in 12 healthy subjects and the relative pulmonary arterial perfusion of the affected lung in all the patients who underwent thoracotomy. The two patients with carcithe patients who underwent thoracotomy. The two patients with carciin the "others," and had relative perfusions of $59 \%$ and $60 \%$. The in the "others," and had relative perfusions of $59 \%$ and $60 \%$. The I. Closed circles $=$ men ; open circles $=$ women.

There was, however, some overlap between the relative perfusion of the affected lung in the patients who were found to be inoperable and the other two groups. Four patients in the inoperable group had only small reductions in the relative perfusion of their affected lung. In one of these with an oat cell carcinoma of the right upper lobe and a relative perfusion of $48.5 \%$, invasion of neighbouring ribs and thoracic vertebrae made the tumour unresectable. There was no involvement of hilar structures.

A second patient, with a carcinoma of the medial segment of the middle lobe and a relative perfusion of $41.5 \%$, was found to have extensive invasion of the pericardium and atria, making the tumour unresectable. A single large gland lay behind the right main bronchus, but the pulmonary vessels were not involved at the hilum.

A third patient, with an anaplastic carcinoma of the right upper lobe and almost no perfusion of this lobe, had generally reduced perfusion of the opposite lung, so that the relative perfusion of the affected lung was $48 \%$. This tumour was unresectable because it had spread around the superior vena cava. Only the right upper lobe vessels were involved at the hilum; the diminution of perfusion of the left lung was not explained.

In a fourth patient (Special Plate, Fig. 4), with a squamous carcinoma of the left lower lobe, perfusion of the affected lung was clearly diminished-the count rate over this lung being $37.5 \%$ of the maximum count rate recorded over the opposite lung-but there were large defects in perfusion of the middle and right lower lobes, so that the relative perfusion of the left lung was $41.5 \%$. This tumour had spared the pulmonary artery, but had invaded the pulmonary veins and spread to the right side of the mediastinum and to the pericardium, making resection impracticable.

The extent of involvement of mediastinal structures observed at thoracotomy is summarized in Table VI. As would be expected, the greatest involvement was found in the patients whose tumours were unresectable. There was a little less involvement in the patients who underwent pneumonectomy and scarcely any involvement in those who underwent lobectomy. The pulmonary vessels were observed to be distorted or compressed by tumour or enlarged glands around the hilum in 23 patients. Actual invasion of the pulmonary arteries by tumour was not seen, though the pulmonary veins were invaded on seven occasions. Invasion of the pericardium and atria was seen only in the inoperable group.

\begin{tabular}{|c|c|c|c|c|}
\hline Operative Findings & Inoperable & $\begin{array}{l}\text { Pncumon- } \\
\text { ectomy }\end{array}$ & Lobectomy & Total \\
\hline 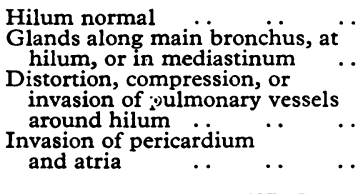 & $\begin{array}{r}1 \\
14 \\
12 \\
8\end{array}$ & $\begin{array}{r}1 \\
13 \\
10 \\
0\end{array}$ & $\begin{array}{r}10 \\
2\end{array}$ & $\begin{array}{l}12 \\
29\end{array}$ \\
\hline
\end{tabular}

\section{Discussion}

Defects in pulmonary arterial perfusion are well known to occur in carcinoma of the bronchus, and such defects are sometimes much larger than the lesion seen on the chest radiograph (Hatch et al., 1965 ; Wagner et al., 1965). Small peripheral tumours, less than $3 \mathrm{~cm}$. in diameter on the chest radiograph, do not produce detectable defects in perfusion, as would be expected from the resolution of the scanning system.

When a tumour is larger than this the defects range from those corresponding to the size of the lesion seen on the chest radiograph to almost absent perfusion of an entire lung. The larger the defect in perfusion the greater is the involvement of mediastinal structures and the more extensive is the surgery required for removal of the tumour.

All the patients in this series in whom perfusion of the affected lung was less than one-third of the total were found to have unresectable tumours. When perfusion of the affected lung was $34-40 \%$ of the total a pneumonectomy was usually necessary. Eleven patients fell into this category, of whom 10 underwent pneumonectomy and one was found to be inoperable. When the relative perfusion was greater than $40 \%$ a lobectomy was usually possible. There were 22 patients in this category, of whom 12 underwent lobectomy, 2 underwent segmental resections, 4 underwent pneumonectomy, and 4 were found to be inoperable.

As lung scans demonstrate only the relative distribution of pulmonary arterial perfusion the presence of defects in perfusion of the unaffected lung may give rise to misleading high values for the relative perfusion of the affected lang.

Minor defects in perfusion of the unaffected lung are common, but sometimes much larger defects may be seen due to chronic bronchitis or emphysema, or to old pulmonary tuberculosis, or more rarely to spread of the carcinoma across the mediastinum (Special Plate, Fig. 4). Garnett et al. (1968) described two cases in which the unaffected lung had less than $40 \%$ of the total pulmonary arterial perfusion. Such patients would clearly be unsuitable for radical surgery. In the two patients in this series who had segmental resections the relative perfusion of the unaffected lung was $41 \%$ and $40 \%$ respectively.

The F.V.C., expressed as a percentage of the predicted value for age, sex, and height, was of less value than the lung scans in distinguishing the inoperable group from the pneumonectomy group and of almost no value in distinguishing the inoperable group from the lobectomy group. None of the patients who underwent pneumonectomy had an F.V.C. less than 
$75 \%$ of of the predicted value, whereas $6(40 \%)$ of the patients in the inoperable group and $3(25 \%)$ of the patients in the lobectomy group did so.

Several mechanisms are probably responsible for the defects in perfusion. Bronchial obstruction is known to reduce blood flow to the affected region (Wagner et al., 1965). In this series perfusion of the affected lobe was moderately or greatly reduced in 11 out of 14 patients with a narrow or obstructed bronchus. Ten of these patients, however, also had impaired perfusion of the adjacent unobstructed lobe, and five patients with normal bronchoscopies had large defects in perfusion, indicating other mechanisms.

The pulmonary arteries may be invaded by tumour, which is unusual, or thrombosed (Hatch et al., 1965 ; Garnett et al., 1968). The pulmonary veins are more often invaded, but the most frequently observed mechanism in our patients was distortion or compression of the pulmonary vessels by the primary tumour or by enlarged lymph nodes along the bronchi and at the hilum.

In patients with clinically and bronchoscopically operable carcinoma of the bronchus preoperative lung scans make it possible to predict with some confidence when a tumour is unresectable. They also give some indication when a pneumonectomy will be required or a lobectomy possible. Fifteen patients in this series $(35 \%)$ were found to have unresectable tumours. In 10 of these perfusion of the affected lung was less than one-third of the total perfusion. If thoracotomy had not been advised in these 10 patients on the basis of their lung scan findings, then the unresectable rate would have been $15 \%$ ( 5 out of 33 ) - a reduction of $20 \%$.
We are grateful to Miss D. Nightingale, Professor R. S. Pilcher, Dr. H. Nicholson, Dr. P. J. D. Heaf, and Dr. P. D. B. Davies for allowing us to study patients admitted under their care. We are also grateful to Miss Judy Jackson, who prepared many batches of $99 \mathrm{mTc}$ MAA and assisted with the scanning procedures. The photographs were kindly prepared by the medical school photographic department.

This work was supported by a generous grant for technical assistance from the British Empire Cancer Campaign.

\section{REFERENCES}

Barrett, R. J., et al. (1963). Fournal of Thoracic and Cardiovascular Surgery, 46, 292

Belcher, J. R., and Anderson, R. (1965). British Medical fournal, 1, 948 .

Chernick, V., Lopez-Majano, V., Wagner, H. N., jun., and Dutton, R. E., jun. (1965). American Review of Respiratory Diseases, 92,

Flavell, G. (1962). British Medical fournal, 1, 284.

Garnett, E. S., Goddard, B. A., Fraser, H. S., and MacLeod, W. M. (1968). British Medical fournal, 2, 209.

Gifford, J. H., and Waddington, J. K. B. (1957). British Medical fournal, 1,723 .

1, 723. Thoracic and Cardiovascular Surgery, 50, 634.

Price Thomas, C. (1960). Thorax, 15,9.

Rogers, R. M., Kuhl, D. E., Hyde, R. W., and Mayock, R. L. (1967). Annals of Internal Medicine $67,947$.

Sabiston, D. C., jun., and Wagner, H. N., jun. (1964). Annals of Surgery, $160,575$.

Secker Walker, R. H. (1968). British Medical fournal, 2, 206.

Steinberg, I., and Finby, N. (1959). American fournal of Roentgenology, Radium Therapy, and Nuclear Medicine, 81, 807 .

Taplin, G. V., Johnson, D. E., Dore, E. K., and Kaplan, H. S. (1964). fournal of Nuclear Medicine, 5, 259.

Wagner, H. N.. Lopez-Majano, V., Tow, D. E., and Langan, J. K. (1965). Lancet, 1, 344.

Wyman, S. M., and Wilkins, E. W. (1958). Fournal of Thoracic and Cardiovascular Surgery, 35, 452.

\title{
Failure of Intravenous Aspirin to Increase Gastrointestinal Blood Loss
}

\author{
ALLAN R. COOKE, $* \ddagger$ M.B., M.R.A.C.P. ; KERRY GOULSTON, $\dagger$ M.D., M.R.A.C.P.
}

Summary : Studies of the effect of intravenous sodium $\checkmark$ acetylsalicylate (aspirin) on gastrointestinal blood loss with ${ }^{51} \mathrm{Cr}$-labelled red cells were made on 15 healthy male volunteers. After a control period of five days $1 \mathrm{~g}$. of sodium acetylsalicylate was infused over a period of 100 minutes twice daily for three days. Faecal blood loss was not increased.

In a further six subjects $3 \mathrm{~g}$. of sodium acetylsalicylate was infused over a period of 120 minutes. No salicylate or acetylsalicylate was detected in saliva or gastric washings from these six subjects. Hence gastrointestinal blood loss induced by aspirin may be explained by a local effect on mucosa and not by any systemic effect.

\section{Introduction}

Most subjects ingesting about $3 \mathrm{~g}$. of unbuffered aspirin daily develop occult gastrointestinal bleeding (Grossman, Matsumoto, and Lichter, 1961; Goulston and Skyring, 1964 ; Smith and Smith, 1966; Beeken, 1968). Systemic administration of aspirin has been reported to cause occult gastrointestinal blood loss in man (Grossman et al., 1961) and gastric erosions with bleeding in animals (Barbour and Dickerson, 1938 ; Clark and Adams, 1947 ; Lynch, Shaw, and Milton, 1964 ; Brodie and
Chase, 1967). The doses used to show a systemic effect in man and animals were large, and were given in so short a period that it was possible that aspirin may have had a general toxic effect, or diffused into upper gastrointestinal secretions and acted by a local mechanism. There have not been any studies in man using smaller and more usual doses of aspirin.

The aim of the present study was to measure faecal blood loss in response to a dose of intravenous aspirin known to cause gastrointestinal bleeding when given orally.

\section{Methods}

Studies were made on 15 healthy male volunteers aged 21 to 23 years. All subjects ate an unrestricted diet and did not ingest any compound containing salicylates during the study. Faecal blood loss was measured by a chromium-51 red blood cell labelling method (Goulston and Skyring, 1964). Collection of faeces was started 48 hours after labelling of red blood cells, and a disposable paint tin was used for each 24-hour faecal

* Senior Research Fellow.

† Honorary Assistant Physician.

A. W. Morrow Department of Gastroenterology, Royal Prince Alfred Hospital, Camperdown, N.S.W., Australia.

‡ Supported by a Fellowship from the National Health and Medical Research Council, Australia. 

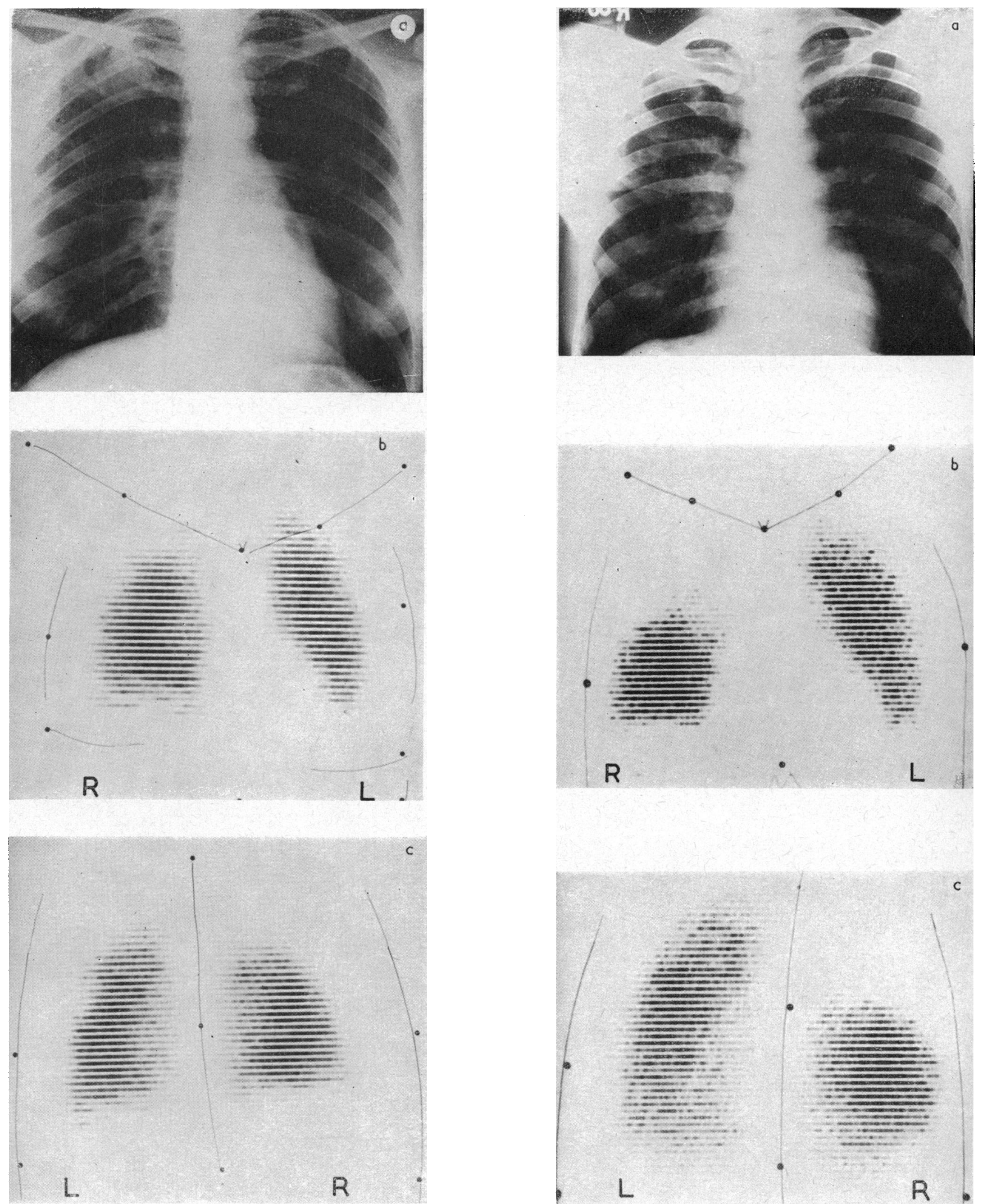

FIG. 1

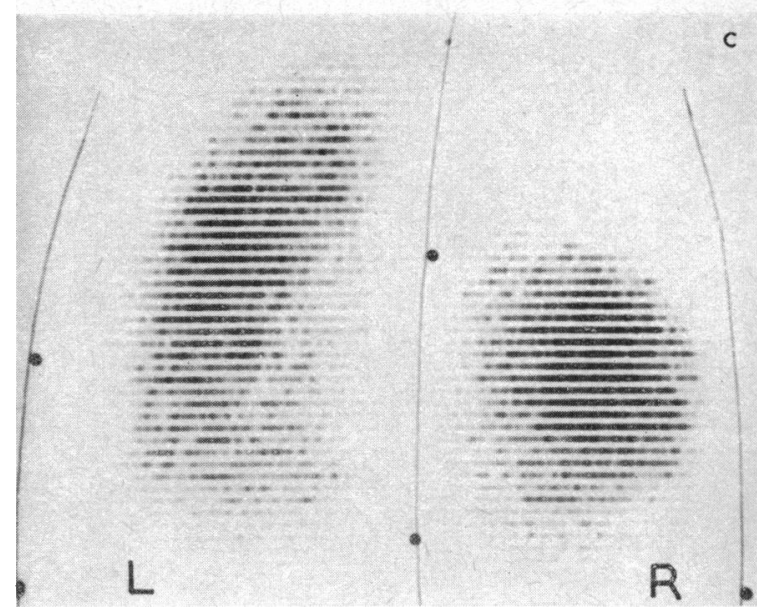

Fig. 2

FIG. 1.-(a) Chest radiograph of woman aged 48 with adenocarcinoma of right upper lobe who subsequently underwent a right upper lobectomy. $(b$ and $c)$ Anterior and posterior photoscans showing a defect in perf usion in right upper lobe which corresponds to tumour seen in chest radiograph. Minor irregularities in perfusion are present on left side.

FIG. 2.-(a) Chest radiograph of man aged 41 with squamous carcinoma of right upper lobe. There is patchy shadowing of right upper lobe and enlargement of right hilum He subsequently underwent right pneumonectomy (b and $c$ ) Anterior and posterior photoscans showing absent perfusion of right upper lobe. 
R. H. SECKER WALKER AND J. L. PROVAN: SCINTILLATION SCANNING OF LUNGS
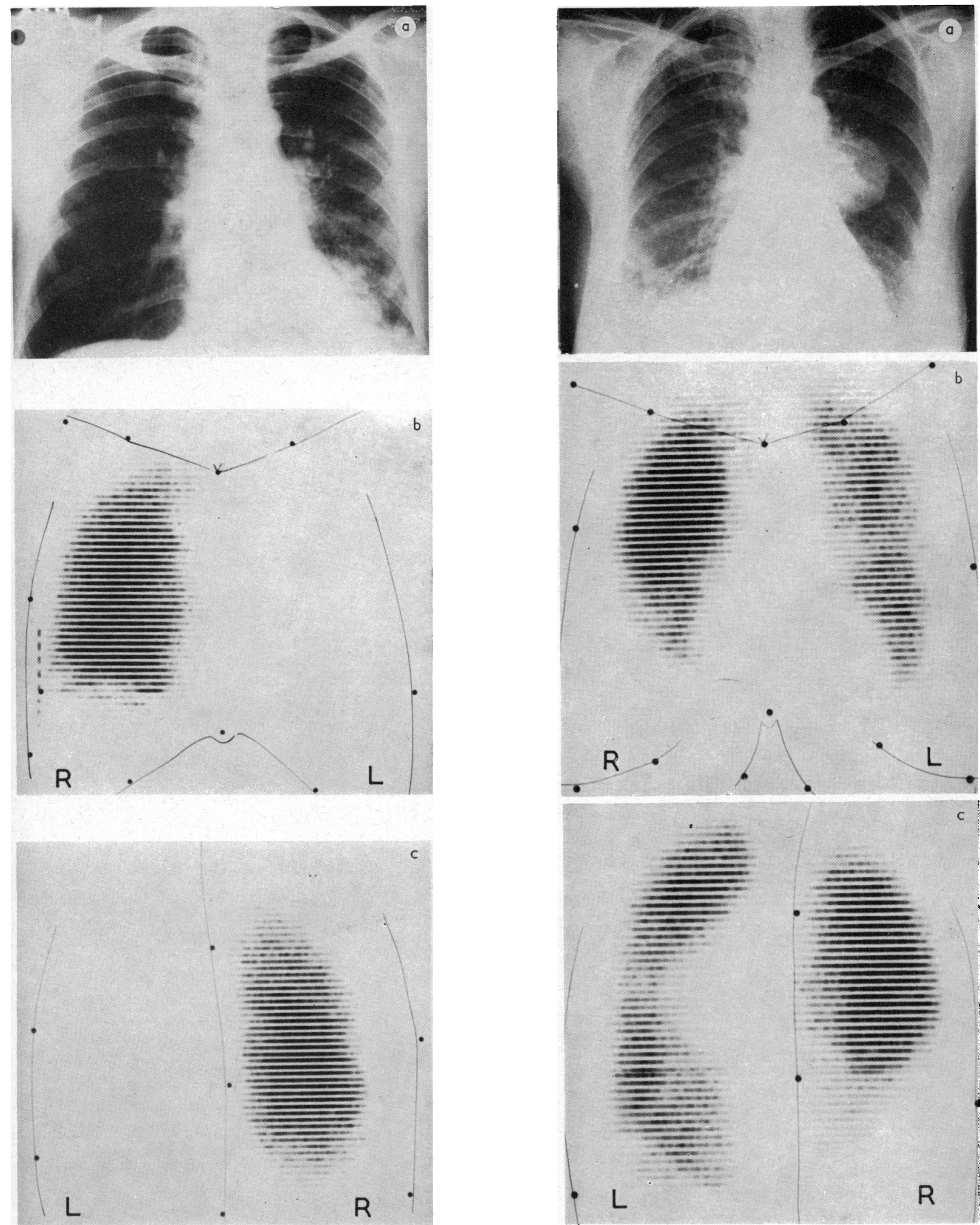

Fig. 3
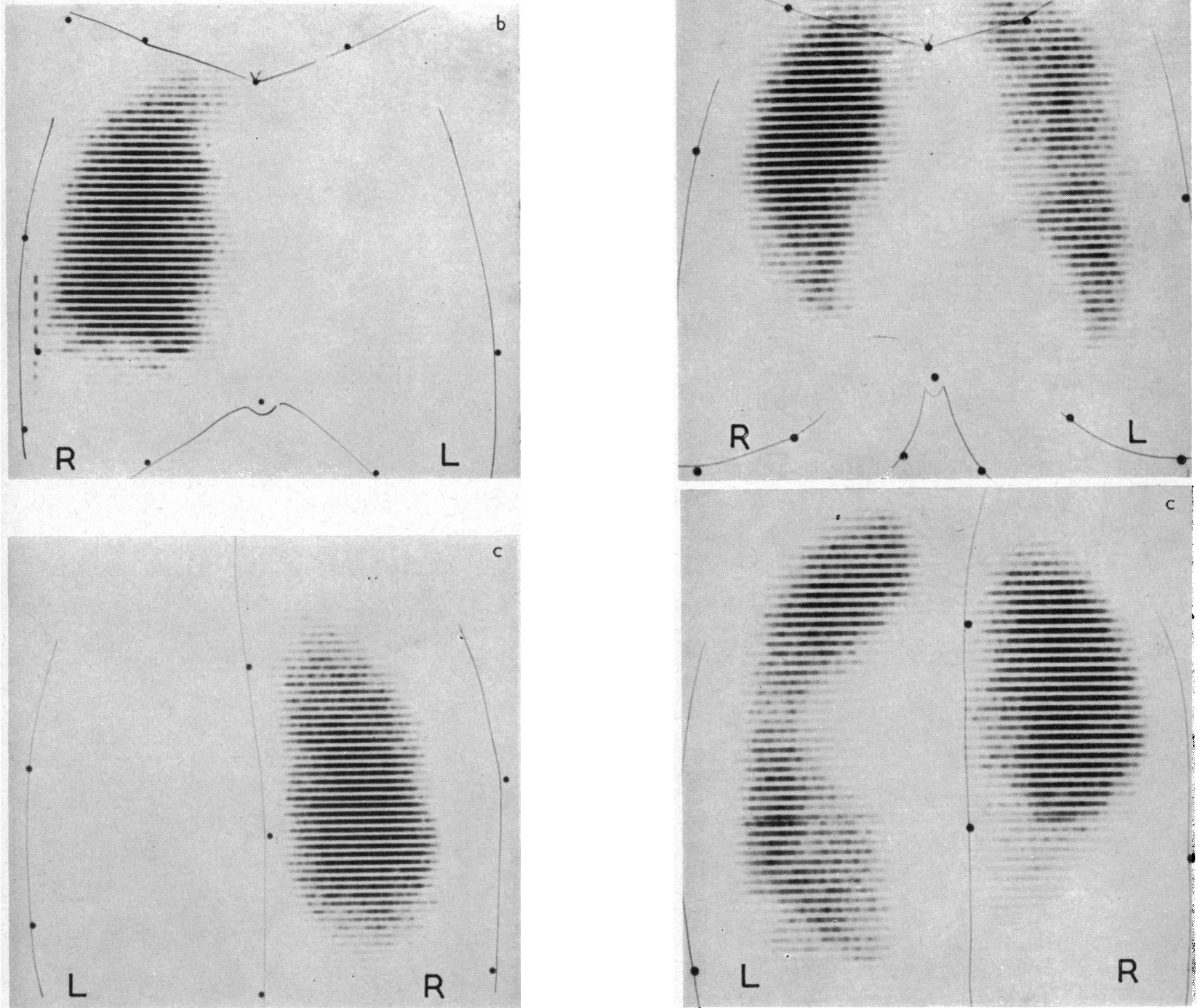

FIG. 4

Fig. 3.-(a) Chest radiograph of man aged 46 with squamous carcinoma of left lower lobe. There is patchy consolidation of left lower lobe and some enlargement of left hilum. At thoracotomy the tumour was inop orable. (b and $c$ ) Anterior and posterior photoscans showing absent perfusion of left lung. Fig. 4.- (a) Chest radiograph of woman aged 65 with squamous carcinoma of left lower lobe. There is a well-defined mass adjacent to the left
hilum. At thoracotomy the tumour was inoperable. ( $b$ and $c$ ) Anterior and posterior photoscans. Perfusion is reduced to whole of left lung with hilum. At thoracotomy the tumour was inoperable. ( $b$ and $c$ ) Anterior and posterior photoscans. Perfusion is reduced to whole of left lung with
a large defect corresponding to tumour which is best seen in posterior view. In addition there are defects in perfusion in the middle lobe and a large defect corresponding to tumour which is best seen in posterior view. In
at the right base. 